\title{
Carl Hampus Lyttkens: Economic analysis of institutional change in ancient Greece: politics, taxation and rational behaviour
}

\section{Routledge, 2013}

\section{Nicholas Kyriazis}

Published online: 13 November 2013

(C) Springer Science+Business Media New York 2013

The present book presents an economic analysis of the causes and consequences of institutional change in Ancient Athens, using methods and concepts of New Institutional Economics, like bounded rationality, agent-principal problem and the theory of credible commitment. Thus, the book sheds light on different issues and asks different questions that tend to be neglected by historians and includes a new look to well-known political figures who introduced political and institutional change, like Solon, Cleisthenes and Pericles.

Of a particular interest are the chapters on taxation, protection of "brand names", election by lot and protection of property rights. The case study Ancient Athens, as the first democracy to emerge, provides a consistent framework that allows the application of its conclusions to the modern world, which the author does with parallels to modern Sweden, Greece and the EU. Relevant lessons include the ubiquity of unforeseen consequences, the fact that motivation for change usually comes from people trying to prevent something unpleasant from happening rather than trying to achieve some positive and specified goal (the cases of Solon's and Cleisthenes' reforms).

The book contains a rich list of references, is very readable, with a sense of humour and is addressed not only to economists, economic historians and classical scholars, but also sociologists and political scientists, as well as all those who are interested in explaining social change and the workings of democracy.

\footnotetext{
N. Kyriazis $(\square)$

Department of Economic, University of Thessaly, Volos, Greece e-mail: nkyr@ergoman.gr
} 